\title{
El esclavo de su esclavo de Mariana de Carvajal: fuentes literarias y reconfiguración de la lealtad en una novela corta del siglo XVII

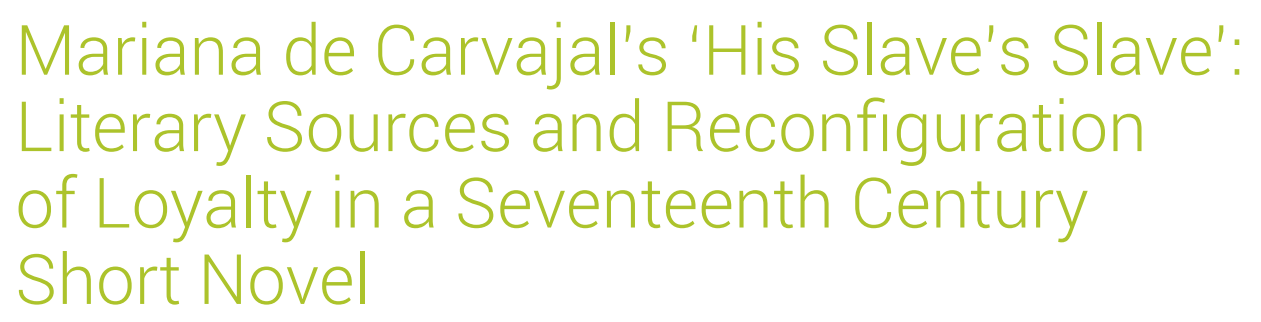

\section{Fernando Rodríguez Mansilla}

http://orcid.org/0000-0001-6429-7307

Hobart and William Smith Colleges

ESTADOS UNIDOS

Mansilla@hws.edu

[Hipogrifo, (issn: 2328-1308), 9.1, 2021, pp. 1011-1026]

Recibido: 25-01-2021 / Aceptado: 08-04-2021

DOI: http://dx.doi.org/10.13035/H.2021.09.01.56

Resumen. Este trabajo se propone explorar el manejo de las probables fuentes literarias de El esclavo de su esclavo y sus implicancias en la construcción del significado del texto. Yendo más allá de la identificación del Abencerraje, me interesa contextualizar su influencia y a la vez analizar otros elementos compositivos de la novela, siempre alrededor de la temática morisca y su rol para brindar un ejemplo sobre la masculinidad y sus virtudes (especialmente la lealtad) en el contexto de la novela corta barroca.

Palabras clave. Mariana de Carvajal; novela corta; Abencerraje; lealtad; Castillo Solórzano; El esclavo de su esclavo; Calderón.

Abstract. This article explores the probable literary sources of El esclavo de su esclavo by Mariana de Carvajal, and how they participate in the construction of meaning within the text. Going beyond the identification of the Abencerraje, I try to contextualize its influence as well as to analyze other compositional elements of 
this short novel. The analysis focuses on the morisco theme and its role to develop an exemplary narrative about masculinity and masculine virtues (especially loyalty) in the context of the Baroque short novel.

Keywords. Mariana de Carvajal; Short novel; Abencerraje; Loyalty; Castillo Solórzano; His Slave's Slave; Calderón.

El esclavo de su esclavo es una novela incluida en la colección Navidades de Madrid (1663) de Mariana de Carvajal, una de las escritoras más destacadas del Siglo de Oro. Hace varios años, María Soledad Carrasco Urgoiti detectó y analizó lo que ella denominó «una huella» del Abencerraje en la escritura de esta novela de Carvajal que puede caracterizarse más precisamente como «novela de cautiverio» o «novela de aventuras». La imitación propiamente dicha que lleva a cabo Mariana de Carvajal del Abencerraje es analizada en detalle por Carrasco Urgoiti y a sus páginas remito para un análisis de los respectivos pasajes ${ }^{1}$. Este trabajo, por su parte, se propone explorar el manejo de sus probables fuentes literarias y sus implicancias en la construcción del significado del texto. Yendo más allá de la identificación del Abencerraje, me interesa contextualizar su influencia y a la vez analizar otros elementos compositivos de la novela, siempre alrededor de la temática morisca y su rol para brindar un ejemplo sobre la masculinidad y sus virtudes (especialmente la lealtad) en el contexto de la novela corta barroca. Como se sabe, este género literario se propone debatir valores y prácticas culturales (linaje, consumo, ostentación, etc.) de una nobleza nueva, aquella afincada en las ciudades, que es tanto protagonista de sus relatos como su consumidora primaria ${ }^{2}$. Bajo ese marco interpretativo, mi enfoque en la masculinidad que desarrolla El esclavo de su esclavo no pretende descartar el rol de lo femenino, sino más bien complementarlo, dado que la actuación de las figuras femeninas (Blanca, Matilde y Jarifa) y la función del silencio de la mujer en la novela ya han sido analizadas de forma convincente ${ }^{3}$.

Debemos empezar reconociendo que esta novela reflejaría «la práctica de incluir una novela morisca o de cautiverio en las colecciones de novela corta»4; en esa medida, nos hallamos frente a una escritura, la de una narrativa de aventuras, que se somete a ciertos convencionalismos y a inevitables reminiscencias ${ }^{5}$. En El

1. Carrasco Urgoiti, 2005, pp. 168-170. Como indica la investigadora, la imitación que lleva a cabo Carvajal contiene paralelismos que reflejarían el recuerdo de una lectura lejana.

2. Remito a Romero-Díaz, 2002, para el desarrollo a profundidad de este planteamiento. Otra aproximación relevante sobre la novela corta es la de E. Rodríguez Cuadros (1979), quien la denominó novela corta marginada, un género narrativo que debía comprenderse como parte de la literatura de mercado y el lector-masa, en el marco de la cultura dirigida que caracterizaba, según lo esbozó José Antonio Maravall, el periodo barroco; igualmente resulta de interés el enfoque más reciente de $\mathrm{M}$. Albert, quien estudia la novela corta como género de cariz didáctico que aglutina saberes varios (2013).

3. Romero-Díaz, 2001. En torno a la particular masculinidad que diseña Carvajal en sus textos (aunque analizando otras novelas suyas), remito a Albert, 2016.

4. Martín Gómez, 2003, p. 73

5. En la parcela de la novela corta, las tramas de aventuras beben de la novela bizantina y se ciñen a varias convenciones: ambientes idealizados, personajes estereotípicos, una intriga esquemática alrededor 
esclavo de su esclavo, Carrasco Urgoiti identifica que «la peripecia yuxtapone tres historias de amor correspondido, enlazándolas a través de un ejemplo de amistad caballeresca» ${ }^{6}$, precisamente el tema del Abencerraje. Las tres historias amorosas son estas: la de Félix y Blanca, quienes conciben a Matilde; Audalia y Jarifa; y la de Feliciano (quien libera a Audalia para que este le devuelva el favor luego) y Matilde (hija de su amigo Félix). Los obstáculos de estas historias son diáfanos: para Félix y Blanca, la oposición del hermano de esta, el conde de Barcelona, quien tendrá que morir para que puedan expresar su amor abiertamente; para Audalia y Jarifa, el cautiverio del moro en España, a quien su generoso captor deja marchar; para Feliciano y Matilde, el cautiverio en Argel, del que los salva el agradecido Audalia. Con estos datos, se hace evidente que El esclavo de su esclavo tiene una estructura tripartita: la primera parte, que opera como una prehistoria, serían los amores de Félix y Blanca, quienes engendran a Matilde; la segunda es el cautiverio de Audalia, con su liberación, episodio que evoca directamente el Abencerraje y podría decirse que lo homenajea; la tercera es el cautiverio de Matilde y Feliciano, y la intervención generosa de Audalia y su amada Jarifa, quienes ayudarán a escapar a los cristianos para ir ellos también a España a bautizarse.

El inicio de la novela, su prehistoria, con los caballeros Félix y Feliciano, recuerda el viejo cuento de los dos amigos, aunque aquí apenas se insinúa: Feliciano y Félix gobiernan Cataluña en nombre del conde Rodulfo, su legítimo señor. Ambos se complementan, ya que Feliciano representaba las armas, «con su mucho valor»?, mientras que Félix tenía «el absoluto gobierno» 8 , personificando el rol de las letras o el ejercicio de la ley, como se entendía por entonces ${ }^{9}$. A veces, como en algunos relatos de Cervantes o una novela corta como Las fortunas de Diana de Lope de Vega, los dos amigos son puestos a prueba por la intervención de una mujer en la trama; en El esclavo de su esclavo, en cambio, el desenlace demuestra que la amistad entre los dos caballeros queda sellada con el matrimonio de Matilde (la hija de Félix y Blanca, hermana del conde Rodulfo) con Feliciano. Con ello nos encontramos ante una representación de la amistad perfecta, en el sentido de sin fisuras, muy a tono con la atmósfera de altruismo y desenlace feliz propio de la narrativa de Mariana de Carvajal, como lo sintetiza Shifra Armon: «The most courteous, discriminating, and urbane rival always wins in Carvajal's novellas, which renders them

del amor e intervención del azar. Un buen resumen de estos mecanismos narrativos se encuentra en Krömer y Dunn (1983). En términos de tipología, el texto de Carvajal posee varias características de la «novela de cautividad» que trazó Teijeiro Fuentes para historias de cautivos en Berbería y Turquía (1988, pp. 49-57). Más recientemente, Hutchinson (2016) identifica El esclavo de su esclavo como parte de lo que denomina «literatura fronteriza mediterránea».

6. Carrasco Urgoiti, 2005, p. 167.

7. Carvajal, El esclavo, p. 430.

8. Carvajal, El esclavo, p. 430.

9. Sobre el cuento de los dos amigos como representación de la amistad perfecta, consistente en fidelidad y altruismo, consúltese Gil-Osle, 2013, pp. 21-27. 
realiable as models of polite conduct» ${ }^{10}$. Teniendo claro el mensaje que pretende transmitir el texto, conviene fijarse entonces en cómo la novelista construye este modelo de conducta cortés.

Como señala Carrasco Urgoiti, lo más verosímil es que Mariana de Carvajal haya conocido la versión del Abencerraje incluida en Los siete libros de la Diana (1562) de Jorge de Montemayor, en lugar de alguna de las otras dos (la del Inventario de Antonio de Villegas y la Crónica), mucho menos accesibles en su época ${ }^{1}$. El Abencerraje que se contiene en La Diana sobresale por atenuar los marcados contrastes entre el estoico y viril Rodrigo de Narváez y el moro sentimental de las otras versiones, poniéndolos casi a la par en masculinidad y valor'². En términos de Maxime Chevalier, la presencia del Abencerraje contribuía con un elemento más bien caballeresco que se incorporaba al neoplatonismo y el mito arcádico que desarrollaba la novela pastoril13. En suma, lo que nos encontramos en la versión de la Diana es una «expresión cortesana» del Abencerraje ${ }^{14}$. Este es el Abencerraje que pudo leer Mariana de Carvajal, más refinado, en el empaque de la Diana de Montemayor, y sin el énfasis en el estoicismo del cristiano en desmedro del moro que se hallaba en la versión que ahora estimamos más (la del Inventario). Esto es lo que permite, probablemente, que los personajes de Feliciano y Audalia acaben igualados, tanto en virtudes como en prestigio social en sus respectivos ámbitos ${ }^{15}$. Si bien, en términos de género, puede comprenderse esta novela también como un acto de apropiación de un texto "masculino" como lo era el Abencerraje ${ }^{16}$, dicha apropiación se realizaría para recrear nuevamente una masculinidad heroica a través de sus personajes varones, con el interés de proponer seguramente una contrafigura al temido afeminamiento que denunciaban los discursos moralistas del siglo XVII ${ }^{17}$.

En El esclavo de su esclavo, Audalia asume el rol del Abencerraje ${ }^{18}$, tomado prisionero y apesadumbrado por no poder reunirse con su amada (que se llama precisamente Jarifa), en tanto Feliciano pasa a ocupar el papel de Rodrigo, el honorable caballero cristiano. La liberación prometida por Feliciano lleva a Audalia a manifestarle su gratitud a través de la imagen de la esclavitud: «Si cumples tu palabra, poderoso y noble catalán, yo te juro, por Alá, que yo y mi amada Jarifa seremos eternamente tus esclavos» ${ }^{19}$.

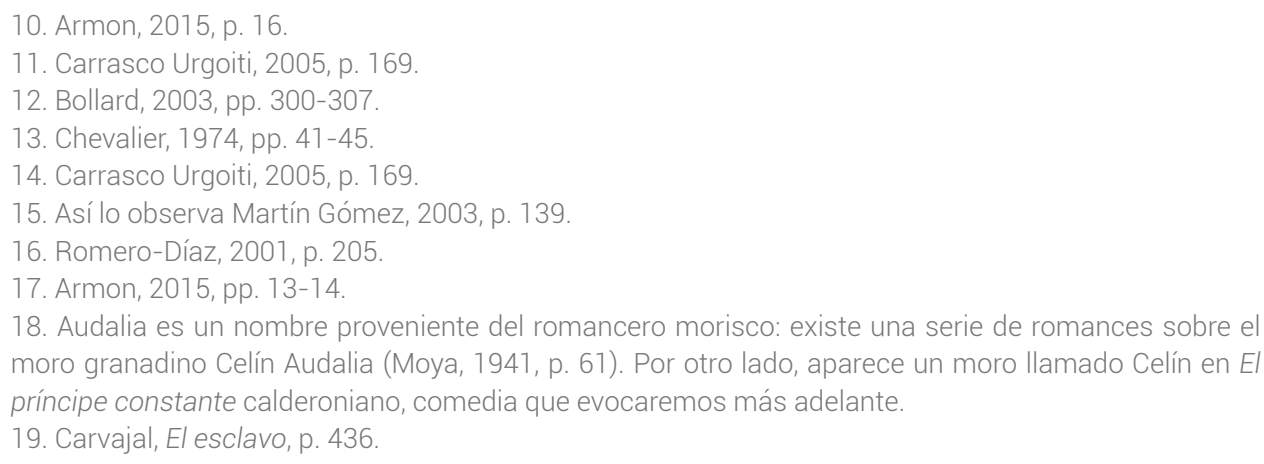


La expresión echar una ese y un clavo puede ayudarnos a entender la imagen referida por el personaje cuando afirma que él y Jarifa serán «eternamente tus esclavos». Según el Diccionario de autoridades, con ella se quiere dar a entender

[la] obligación y reconocimiento que uno debe o profesa como agradecido a otro [...]. Esta metáfora y locución tiene su origen de lo que se hace con el esclavo, a quien se le suele herrar en el rostro o parte conocida del cuerpo, y se le pone la cifra del nombre esclavo con una S y un clavo enlazados ${ }^{20}$.

La obligación o deber que se asume es la lealtad. De hecho, la esclavitud que imponen los afectos ya se plasma en uno de los versos que Félix cantaba para enamorar a Blanca al inicio de su cortejo, en la prehistoria de la novela: «Pues gustáis de matarme, / yo moriré contento, / si el esclavo leal, / siempre obedece al dueño» ${ }^{21}$. La esclavitud opera como una efectiva imagen de la lealtad, que se aplica por igual a la pasión amorosa como a la gratitud debida. El concepto de la lealtad ya se encontraba en el Abencerraje con esta misma ambivalencia. En la novela anónima, tras reencontrarse con Abindarráez, Jarifa se siente incómoda por la melancolía del moro, que con suspiros recuerda, en silencio, la promesa de volver a la prisión. La dama, que ignora el caso, percibe una «tan grande ofensa de su hermosura y lealtad» 22 , como amante, pues teme que él ya no la quiera (y por ende que ya no le sea leal). Sin embargo, el Abencerraje le explicará que aquellos suspiros tristes «se causan más de sobra de lealtad, que de falta della» ${ }^{23}$, en referencia a la lealtad, precisamente, que debe guardar a las palabras que dio al cristiano Rodrigo. En el Abencerraje no se emplea, por otra parte, «esclavitud» o «esclavo», sino «prisión» o «prisionero», ya que estos últimos términos son los apropiados para describir las consecuencias de las escaramuzas en la frontera. De esa forma, en la novela anónima no se explota la esclavitud como imagen de la lealtad, sino que esta simplemente se denota.

Asimismo, contra lo que mandaba la lección original del Abencerraje, que exigía que el prisionero moro regresara luego de visitar a su dama (algo que Audalia está dispuesto a cumplir), en El esclavo de su esclavo Feliciano pone como condición todo lo contrario: «No quiero yo que vuelvas [...] solo quiero que cumplas tu palabra, no inquietando las costas de Cataluña» ${ }^{24}$. Detrás de esta frase («No quiero yo que vuelvas») bien podríamos encontrar una convicción propia de la época de Carvajal en torno a los moros: que no debían volver. La expulsión de los moriscos (decretada en 1609), ya no es un tema latente para la discusión, como todavía lo era en tiempos de la segunda parte de Don Quijote, cuando era un acontecimiento bastante fresco.

20. Aut.

21. Carvajal, El esclavo, p. 432.

22. Montemayor, Los siete libros de la Diana, p. 216. Cito la versión incluida en la Diana para ser coherente con la más probable lectura de Carvajal.

23. Montemayor, Los siete libros de la Diana, p. 217

24. Carvajal, El esclavo, p. 436.

HIPOGRIFO, 9.1, 2021 (pp. 1011-1026) 
Esta propuesta de Feliciano para Audalia marca a su vez el fin de la imitación del Abencerraje propiamente dicha y se sigue, más bien, lo que podríamos denominar su segunda parte o, en otras palabras, cómo continuaría la historia del moro cautivo y el cristiano en una aventura posterior. Me explico. Como señala Carrasco Urgoiti, tras la liberación de Audalia con la promesa de no atacar al conde de Barcelona, la novela de Carvajal sigue su propio camino al margen del argumento del Abencerraje, «pero de tal forma que una peripecia amplificada recalca la ejemplaridad de la aventura» ${ }^{25}$. Podría afirmarse, entonces, que El esclavo de su esclavo presenta no solo una imitación, sino una continuación del Abencerraje: el moro devuelve el acto generoso del cristiano cuando la situación de cautiverio se invierte. El esclavo de su esclavo sería una especie de segunda parte del Abencerraje, en la que se narra lo que Abindarráez habría hecho si Rodrigo de Narváez hubiese sido cautivo suyo. Si bien el gesto generoso obedece a la lealtad debida, la motivación del caído en desgracia está entrelazada siempre con el amor: Audalia es el enamorado que quiere encontrarse con Jarifa, primero, y luego Feliciano quiere volver a España llevando a su amada Matilde. A propósito, nótese que sería el contacto de Carvajal con la versión de la Diana el que permitiría que ambos personajes masculinos pudieran ser enamorados: Feliciano / Rodrigo y Audalia / Abindarráez no cargan con el contraste del Abencerraje incluido en el Inventario, el cual representaba al moro como un sujeto sentimental, inferior al cristiano que no cae en las tentaciones del amor.

Ahora bien, si el gran tema del Abencerraje era la generosidad (el cumplir la palabra y ser desprendido o liberal con el que está en desgracia), ejerciendo la virtud con personas que no son de la misma religión (del cual se desprende su mensaje de tolerancia), en El esclavo de su esclavo el tema se desplaza hacia la lealtad, que es consecuencia de la gratitud que se siente hacia quien fue inicialmente generoso. El cambio es sutil, pero no debe ser pasado por alto, ya que la lealtad «es la clave que propiciará el desenlace feliz de los protagonistas» ${ }^{26}$. En la novela, la lealtad se propone como un valor que se postula como necesario para el orden social en varios niveles: Blanca es leal hacia Félix, pese a la reticencia de su hermano el conde Rodulfo; en tanto las parejas de Matilde y Feliciano, y Audalia y Jarifa serán leales a la religión católica para salir de Argel. Como resume bien Hutchinson, los personajes de esta novela «se esfuerzan por superarse en generosidad los unos a los otros en un ciclo de enormes favores a través de las barreras étnicas, religiosas y políticas» ${ }^{27}$.

Para Carrasco Urgoiti, la influencia de la novela morisca anónima en El esclavo de su esclavo se encuentra en la relación de cristianos y musulmanes, pero «la diferencia más importante consiste en que Abindarráez ha de volver a prisión, mientras que Audalia solo debe abstenerse de hostigar a los catalanes» ${ }^{28}$. En este punto, en realidad, podríamos encontrar una actitud ortodoxa (o intolerante, si se quiere) de parte de Mariana de Carvajal frente al musulmán, quien, dentro del relato, no es

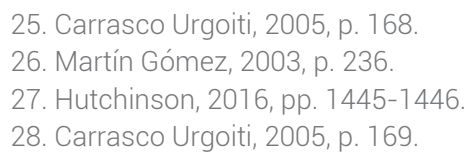

HIPOGRIFO, 9.1, 2021 (pp. 1011-1026) 
bienvenido a tierras cristianas (tal era la propuesta de Feliciano, recordémoslo, para dejar libre a Audalia al inicio), excepto si se convierte; mientras que el cristiano en territorio del islam debe mantenerse leal a su religión. En consecuencia, el personaje de Matilde se mantendrá firme en sus convicciones religiosas, tanto como Feliciano; pese a que a la muchacha se le intenta persuadir y se le ofrecen muchas ventajas para hacer una vida nueva en Argel si se convierte y se desposa con un moro.

Estamos bien lejos, en este punto, de la narrativa, más dramática y emocionante, de la Historia del cautivo, en la primera parte de Don Quijote, que incluía peligros, miedos, la memoria de Lepanto, un renegado que intenta reconciliarse, un padre decepcionado de su hija, etc. En comparación, el conflicto narrativo de El esclavo de su esclavo es mucho más sencillo, aunque no por ello menos ejemplar para los intereses de Mariana de Carvajal: de la mano de dos cristianos (Feliciano y Matilde) que no sufren dudas o tentaciones mayores, contamos con la pareja de musulmanes (Audalia y Jarifa) que quieren convertirse al cristianismo y serán los aliados que cooperarán en la fuga. Es evidente que, en el universo de Carvajal, la lealtad a la fe que se profesa solo se aplica al cristiano, no al musulmán. Catherine Infante apunta, con razón, que «esta concepción unidireccional de la conversión [dado que se privilegia la conversión al cristianismo] estaría sin duda distorsionando el contexto de las relaciones entre ambas religiones, pero por otro lado nos da la oportunidad de vislumbrar la noción y prejuicios con los que se trataban estos temas por algunos autores de la época» ${ }^{29}$.

Ciertamente, para la época en que la novela de Mariana de Carvajal se publica, poco más de cincuenta años después del decreto de expulsión de los moriscos, no cabía lugar en la literatura a debatir en torno al drama interreligioso. Sin embargo, el otro elemento ficcional que evoca el asunto morisco, el cautiverio, pese a ser romantizado por Carvajal a través de la ambientación seudomedieval ${ }^{30}$, era una realidad aún en la segunda mitad del siglo XVII. Existen, por lo años de publicación de Navidades de Madrid, noticias de incursiones de piratas moros en la costa española, como la que denuncia en diciembre de 1670 el obispo de Almería: moros se llevaron a Argel tres hombres y seis mujeres (tres de ellas embarazadas), así como ocho niños. Los frailes redentores lograron pagar el rescate de todos y traerlos de vuelta a España, además de rescatar a tres niños más nacidos en cautiverio ${ }^{31}$. Se entiende así que el tema era de actualidad para los lectores de Carvajal, lo cual enfatiza la pátina literaria que le aplica la novelista y, dicho sea de paso, la naturalidad con la que esta estilización podía llevarse a cabo en la narrativa de entonces.

El episodio argelino, que ocupa la tercera parte de la novela (el cual encierra el gesto recíproco del moro), recuerda más bien a un novelista bastante popular del siglo XVII, Alonso de Castillo Solórzano. Su texto El bien hacer no se pierde, novela $\mathrm{VI}$ de Noches de placer (1631), es un relato que también habla del cautiverio en tierras musulmanas: un cautivo cristiano, Jerónimo, es ayudado por su nuevo patrón, un moro poderoso, Hamete, quien primero lo quiere convertir y casarlo con

29. Infante, 2017-2018, p. 192.

30. Recreación no exenta de anacronismos, como comenta Carrasco Urgoiti, 2005, p. 167.

31. Díaz-Plaja, 1987, p. 315. 
su hermana para sacarlo de la servidumbre; como no lo logra, lo ayuda a escapar de vuelta a España y de paso le da las señas de un tesoro que dejó enterrado allí. Hamete lo ayuda porque Jerónimo lo rescató, mucho tiempo atrás, de un incendio de una alquería en Valencia. Por ello la buena acción inicial del cristiano (segundón de una noble familia valenciana, el tipo de personaje masculino favorito de Castillo Solórzano ${ }^{32}$ ) es devuelta por el moro cuando lo encuentra en desgracia, devolviéndole generosamente el primer favor. En este relato, nos encontramos ante la misma gratitud que genera la lealtad, tema principal de la novela de Mariana de Carvajal, según lo refleja su propio título (en que ser esclavo significa ser leal o guardar gratitud). Tanto en la novela de Castillo Solórzano como en la de Mariana de Carvajal el personaje del moro pertenece a una familia de abolengo en su tierra, por lo que la virtud se identifica como elemento intrínseco de la nobleza, más allá de las diferencias religiosas ${ }^{33}$.

Como sería de esperar, en El bien hacer no se pierde, Castillo Solórzano refiere la versión ortodoxa de la expulsión de los moriscos, dado que se deja entrever el peligro de su presencia en la península como una quinta columna ${ }^{34}$. Sin embargo, más interesante resulta el hecho de que, más allá de la gratitud de Hamete hacia Jerónimo por haberle salvado la vida, en ningún momento se aborda en el relato una posible conversión del moro al cristianismo. Si en El esclavo de su esclavo Carvajal proponía la asimilación religiosa del moro como remedio, esencial, para consolidar la amistad y la convivencia, para Castillo Solórzano ni siquiera aparece como opción. Sería gratuito atribuirle al escritor vallisoletano una particular intolerancia o rechazo frente al musulmán. Como señala Herrero García, la literatura popular no dejó de celebrar la expulsión y, si bien hubo voces que lamentaron ese desenlace y sus consecuencias para el país (sobre todo las económicas), nadie objetó el hecho en sî35.

32. La narrativa del vallisoletano suele contar con protagonistas masculinos que son segundones, es decir hijos que, sin posibilidad de acceder a la riqueza de la familia (reservada para el primogénito o mayorazgo), deben demostrar su virtud con habilidades como el ingenio y el valor.

33. En realidad, este enaltecimiento del moro, aunque sea enemigo de religión, es un rasgo compartido por los textos del género morisco (Teijeiro Fuentes, 1988, pp. 17-25).

34. En El bien hacer no se pierde, cuando se produce la anagnórisis, en Argel, de Hamete con su antiguo salvador, el moro, cuya familia vivía en Valencia, le cuenta al cristiano cómo los suyos mantenían contacto con sus familiares argelinos y los planes urdidos de pillaje y conquista entre ambas orillas: "Mi abuelo y mi padre siempre tuvieron correspondencia en Argel, porque a esta ciudad descienden de la más calificada familia della, y muy caballeros. Tenían, pues, unos con otros trato de secreto, y con segura ganancia se enriquecían. La causa de no venirse mis pasados de secreto a esta tierra fue porque deseaban ver efectuado un levantamiento de nuestra gente contra la vuestra, para hacerse señores de la tierra» (Castillo Solórzano, Noches de placer, p. 254). La idea de los moriscos como quinta columna de los turcos o presuntos aliados del rey francés fue una de las razones más fuertes alegadas para el decreto de expulsión de 1609 (Elliott, 1972 p. 306).

35. Herrero García, 1966, p. 574.

HIPOGRIFO, 9.1, 2021 (pp. 1011-1026) 
Resulta sugerente traer igualmente a cuento, a propósito de los textos de Mariana de Carvajal y Castillo Solórzano, la comedia El príncipe constante de Pedro Calderón de la Barca, que se estrenó en Madrid en 1629, dos años antes de la publicación del texto del vallisoletano en Noches de placer. En El príncipe constante contamos con otra recreación del Abencerraje en el gesto del infante portugués don Fernando liberando al enamorado moro Muley ${ }^{36}$. Este le dirá al cristiano como muestra de su gratitud que «soy tu esclavo eternamente» ${ }^{37}$ y sale del escenario, libre para reencontrarse con su amada Fénix, diciendo que «hacer bien nunca se pierde» 38 , frase que nos lleva directamente al título de la novela de Castillo Solórzano, El bien hacer no se pierde, la cual versa, precisamente, acerca de la gratitud que le guarda el moro Hamete a su redentor Jerónimo Corella. Además de esta posible intertextualidad entre Calderón y Castillo Solórzano, aparece una adicional con Mariana de Carvajal. En la segunda jornada de El príncipe constante encontramos a Muley proponiéndole al infante don Fernando ayudarlo a escapar del cautiverio como muestra de su lealtad, que él identifica, como en la novela de Carvajal, con la esclavitud: «Yo lo soy [esclavo] tuyo, y así / no vengo, infante, a ofrecer / mi favor, sino a pagar / deuda que un tiempo cobré» 39 . Con todo, el infante no aceptará su ofrecimiento, dado que asume con estoicismo su cautiverio, para no perjudicar a Muley. Como resultado, el final del infante don Fernando es trágico y lejano, en ese sentido, de la aventura, con énfasis en la ejemplaridad, garante de un final feliz, que elaboran primero Castillo Solórzano y más tarde Mariana de Carvajal en sus respectivas novelas. Esta escritora bien pudo acceder a la lectura de Calderón (quien incluyó El príncipe constante en la Primera parte de sus comedias, publicada en 1636) e identificar igualmente la esclavitud como imagen clave para reflejar la lealtad debida como tema central de la novela y su título mismo ${ }^{40}$.

Volviendo a la influencia del Abencerraje en la novela de Carvajal, si bien su imitación se restringe a la segunda parte (la liberación de Audalia), se podrían identificar al menos dos huellas más de cómo su lectura permaneció en la memoria de la novelista, otra muestra acaso de aquella invisible continuación que indicábamos más arriba. Primero, en la escena en que Feliciano, bajo el disfraz del moro Mostafá, baila y canta cortejando a Matilde, se observa que, al final de su danza, le ofrece un ramillete de mosquetas (especie de rosas blancas), que ella recibe con palabras de-

36. Se trata de un episodio célebre, aunque secundario, que participa de la sofisticada construcción de lo que se suele considerar una «tragedia de mártir», por su protagonista, el infante don Fernando, quien renuncia a su libertad en defensa de la fe de los habitantes de una cristiana Ceuta (Arellano, 1995, pp. 488-489).

37. Calderón de la Barca, El príncipe constante, p. 33.

38. Calderón de la Barca, El príncipe constante, p. 34

39. Calderón de la Barca, El príncipe constante, p. 67.

40. Queda por demás tal vez señalar que Calderón de la Barca era un dramaturgo bien conocido, pero conviene de todos modos recordar que Castillo Solórzano lo menciona elogiosamente en las Aventuras del bachiller Trapaza (1637), en su catálogo de los autores más prestigiosos en las tablas de la época: «Encarecieron los ingenios que ahora lucen, como son: un fénix de la poesía, Fr. Lope de Vega Carpio, don Mescua, don Pedro Calderón, don Montalbán, un dotor Godínez...» (Castillo Solórzano, Aventuras del bachiller Trapaza, p. 264).

HIPOGRIFO, 9.1, 2021 (pp. 1011-1026) 
corosas $^{41}$. En el Abencerraje, el enamorado Abindarráez se presenta con una guirnalda de flores igualmente blancas (jazmines y arrayanes) en la cabeza, que Jarifa le quita para coronarse ella misma ${ }^{42}$. Otro indicio del Abencerraje puede encontrarse en los regalos suntuosos que envía Félix al rey moro en agradecimiento por el buen trato hacia Matilde en su cautiverio: además de vestir ricamente a los moros que vuelven a Argel, envía prendas para la sultana, caballos y monedas de oro. «Lo envió todo al rey, diciéndole en una carta que no le enviaba a Audalia y a Jarifa porque habían recibido el santo bautismo, y que Matilde era su hija y le enviaba aquel presente en rescate» ${ }^{43}$. De manera similar, el padre de Jarifa, en el Abencerraje, le proponía a Abindarráez enviar a Rodrigo de Narváez una serie de obsequios:

Que no por haber usado con vosotros de tanta virtud y gentileza, es razón pierda el derecho de vuestro rescate, antes se le debe, si bien se mira, muy mayor; yo os quiero dar cuatro mil doblas zaenes; enviádselas y tenelde desde aquí adelante, pues lo meresce, por amigo, aunque entre él y vosotros sean las leyes diferentes ${ }^{44}$.

Dicho esto, los detalles suntuosos en el desenlace de El esclavo de su esclavo trascienden la posible referencia al Abencerraje y adoptan un significado mucho más específico: el de expresar una identidad noble que se desprende del origen musulmán y se cristianiza; ya que a los presentes referidos para el rey de Argel se añaden las pinturas que se manda hacer para exaltar la intervención de la Virgen de Monserrate y otra que reflejase la aventura de los recién cristianizados Audalia y Jarifa. Infante ha analizado la práctica devota de las pinturas de la Virgen con donantes, que la última parte de la novela recrea, como medio de exaltación tanto religiosa como de estatus social, dado que este tipo de representación solía integrarse en las cartas de ejecutoria que demostraban la hidalguía ${ }^{45}$. Armon igualmente comenta que esta exhibición de riqueza y devoción al final de la novela debía confirmar, frente a los cristianos, la sinceridad de la conversión de la pareja de moros recién convertidos 46 .

41. La escena sería muestra de ese hombre "femenino" propio del universo narrativo de Carvajal, un sujeto sensible, con habilidades artísticas (poesía, canto, el baile) para el cortejo, que también aparece en otros textos suyos (Albert, 2016, p. 206).

42. «Entonces ella puso los ojos en mí más dulcemente al parescer, y quitándome la guirnalda la puso sobre su cabeza, paresciendo en aquel punto más hermosa que Venus» (Montemayor, Los siete libros de la Diana, p. 211). Esta escena del Abencerraje contó con recreaciones quizás más cercanas en el siglo XVII; una de ellas se presenta en la novela La ingratitud hasta la muerte de Francisco Lugo y Dávila: el protagonista, Floristo, entrega una guirnalda, en un ambiente de tintes caballerescos, como prenda de amor a su dama (quien se ofuscará) con las siguientes palabras: «Vencí en el bosque a mis enemigos y de haberme vencido te corono» (Novelas cortas del siglo XVII, p. 191).

43. Carvajal, El esclavo, p. 446

44. Montemayor, Los siete libros de la Diana, p. 221. Junto a las doblas del suegro, Abindarráez regala caballos, adargas y lanzas de oro; Jarifa añade una caja de ciprés y ropa blanca.

45. Infante, 2017-2018, pp. 195-198.

46. Armon, 2002, p. 75. 
La esmerada fastuosidad del desenlace incluye, por último, una procesión de la imagen de la Virgen por calles que son a su vez adornadas, como en una fiesta religiosa típica del Barroco ${ }^{47}$. Con esta escena, nos hallamos ante uno de los elementos compositivos más característicos de la narrativa de Mariana de Carvajal, el de la ostentación como medio de distinguir la nobleza verdadera ${ }^{48}$. En particular, Eavan O'Brien ha resaltado la función de los marcos narrativos en los que se representa la ostentación y el ocio a través de mobiliario, escenarios (como jardines y fuentes) y comida como parte del significado de los relatos: estos elementos confirmarían la categoría de los personajes elevados ${ }^{49}$. Este rasgo es constante en la narración de Carvajal y hace que incluso la aventura se encuentre marcadamente estilizada o parezca hasta cierto punto artificial para el gusto moderno. Así, por ejemplo, se describe el ambiente deleitoso en el que el personaje de Alberto, el tutor de Matilde, le cuenta su historia a Feliciano: «Y sentándose en la basa de una hermosa fuente, debajo de unos capados naranjos, le contó quién era Matilde...» ${ }^{50}$. Como señala Armon, los narradores y los personajes de Carvajal «ejecutan elaborados rituales corteses que sirven para medir el estatus social de cada uno» ${ }^{51}$. Este ambiente refinado que impregna toda la aventura del cautiverio refleja la caracterización que Louis Imperiale ha hecho del mundo narrativo de Mariana de Carvajal:

In the case of Doña Mariana, we could discuss femenine "bourgeois" literature, in which the importance that is granted to courting, dance, refinement, elegance of fashion, good manners, musical aesthetics, pleasure of cuisine, etiquette, and good taste signals to us that the rites and privileges reserved for the nobility were being extended to the middle class ${ }^{52}$.

Algo similar podría señalarse en torno a la escena de Feliciano, bajo el disfraz del moro noble Mustafá (supuesto primo de Audalia), que encandila a los presentes de una reunión social, bailando y cantando, como referimos antes. Se trata de una escena festiva que no desentona del todo en una trama de antemano dulcificada por las descripciones de un ambiente deleitoso y diálogos distinguidos. Un elemento más de esta artificialidad, admisible dentro de su contexto, sería la diferencia de edad entre Feliciano y Matilde, un rasgo que podría sentirse poco verosímil en la actualidad $^{53}$. Lo cierto es que la verosimilitud se construye alrededor de las convenciones narrativas del caso, como se puede comprobar con los tantos anacronismos que se pasan por alto sin problema en la ficción del Siglo de Oro. La diferencia de edad de la pareja de amantes podría comprenderse como socialmente acepta-

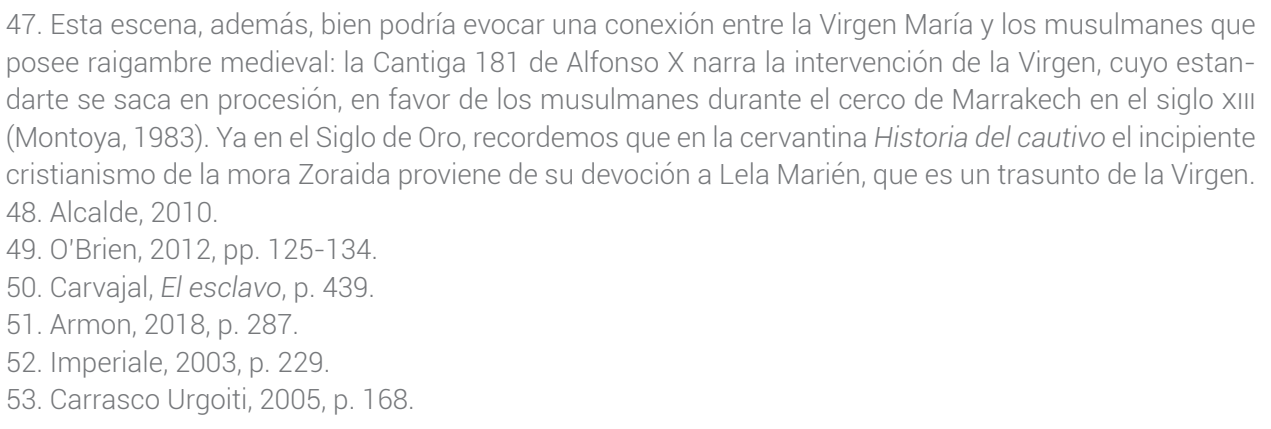


ble si se considera que existía una pareja real que también contaba con una notoria brecha generacional en la época de composición de la novela: Felipe IV y su sobrina Mariana de Austria, quienes se casaron en 1649 y tenían una diferencia de edad de 30 años. Más allá todavía, como lo ha explorado Armon, El esclavo de su esclavo se presta a una lectura alegórica, en la que la superación de los obstáculos para el matrimonio de la joven Matilde y el veterano Feliciano reflejaría los esfuerzos diplomáticos que se llevaban a cabo en la corte por los mismos años de publicación de Navidades de Madrid para casar a la infanta Margarita, la hija de Felipe IV, con Leopoldo I, su tío ${ }^{54}$, aunque la diferencia de edades entre ambos no era tan grande (tan solo once años).

Como observa Armon, la novela demuestra, en el poema del final, que alguien como Audalia, noble moro, puede adaptarse a la condición de cautiverio sin perder su lealtad, propia de su identidad aristocrática ${ }^{55}$. Esto debe hacernos recordar la variedad de miradas sobre el moro en la literatura del siglo XVII, que va desde una visión idealizada como esta hasta la del moro hechicero en una novela como el Desengaño quinto de María de Zayas. Estas imágenes contrapuestas no obedecen necesariamente a ideologías o valores en conflicto, sino a necesidades narrativas: en la novela de Zayas se requiere un personaje foráneo que encarne la maldad y los poderes demoníacos, mientras que en la de Carvajal se requiere a un príncipe generoso en tierras exóticas para esbozar una peripecia satisfactoria para el lector del XVII ${ }^{56}$. Estas imágenes (moro malvado y moro generoso) conviven en la ficción y deben ser evaluadas por su funcionalidad en la trama. Con el mismo pragmatismo narrativo debería comprenderse la adaptación del Abencerraje: se han recogido de él la maurofilia, pero pasada por el filtro de la asimilación religiosa del moro (ahora devoto cristiano), y la marcada artificialidad de una trama que no debe ser juzgada con paradigmas realistas, sino con los propios de una narración en la que los elementos suntuosos están cargados de un valor que dignifica a sus personajes y los convierte en modelos para el lector. En esta novela, especialmente, la aventura pone en primer plano a los dos personajes masculinos, Feliciano y Audalia, quienes ponen sus respectivas virtudes al servicio de una causa mayor: la de la redención de la muchacha, Matilde, para exaltación de la fe y el posterior matrimonio que

54. Armon, 2002, pp. 182-183. Otra lectura alegórica, que engarza la descendencia de Felipe IV y la compleja relación de la Corona con Cataluña, es ofrecida por Romero-Díaz, 2001, p. 208. Por mi parte, no descarto ninguna de las dos interpretaciones regio-alegóricas, pero no las considero necesarias para mi lectura de la masculinidad que recrea la novela.

55. Armon, 2002, pp. 133-134

56. La representación como virtuoso o malvado del personaje obedece más que nada a necesidades estructurales y ambientación (heroísmo dentro del cautiverio y exaltación de la lealtad), antes que provenir de una dicotomía, algo maniquea, pero de larga tradición en la crítica (como bien resume Martín Gómez, 2003, p. 46), según la cual María de Zayas es "rebelde" o "crítica" y Mariana de Carvajal es "conformista" o "conservadora". Sobre esta peliaguda etiqueta de Carvajal como "conformista", Romero-Díaz nos recuerda, por su parte, que el acto de escribir en sí mismo supone un acto de rechazo a la sumisión femenina, por lo que nos hallaríamos aparentemente ante una paradoja (2001, pp. 204). A ello se podría añadir que la insistencia de Carvajal en recrear un ambiente y unos personajes modélicos también supone, por qué no, una cuota de inconformismo y rebeldía frente a lo real cotidiano, que nunca deja de ser mediocre. 
asegurará la continuidad del buen gobierno de los dos amigos, Félix y Feliciano, que serán ahora suegro y yerno. Este desenlace viene de la mano de la conversión, deseada, de Audalia y Jarifa, los moros, igualmente generosos y nobles, que se sumarán a la armonía final.

A este propósito, la adopción de «Félix Feliciano» como nombre cristiano para Audalia simbolizaría la unión de los valores complementarios que cada uno de los dos viejos amigos catalanes representaba (las armas y las letras); un símbolo que se concretiza con la descendencia que Feliciano tendrá con Matilde, hija de Félix. Con el nuevo nombre, dicho sea de paso, el elemento morisco es apartado o, si se quiere, vuelto un recuerdo heroico dichoso, pero ya no un factor de tolerancia o integración, como se lo proponía la historia del Abencerraje en la segunda mitad del siglo XVI. Por último, como recuerda Romero-Díaz, ambos nombres (Félix y Feliciano) remiten a una misma raíz latina que significa 'fertilidad'57, precisamente aquello de lo que carecía el conde Rodulfo (quien «era incapaz de engendrar» ${ }^{58}$ ) y es el origen del conflicto y las peripecias alrededor de él: Blanca no podía enlazarse públicamente con Félix, de allí que tuvieran que criar a su hija a escondidas, una condición que propicia su captura, etcétera. Así, el desenlace no solo es una exaltación de la nobleza de estos hombres a través de la ostentación y los actos tanto heroicos como generosos que se relatan, sino que también encierra la promesa de un buen gobierno ostentado por sus descendientes, pues «tuvo Matilde dos hijos varones, que reinaron después con gloriosa memoria» ${ }^{59}$. Con todos los elementos de la trama, Carvajal apunta a que esta conclusión es producto de los esfuerzos de una comunidad de personajes virtuosos, elegantes y devotos cristianos.

Este sentido de comunidad es el que recrea, en general, la narrativa de Mariana de Carvajal para sus lectores, sujetos urbanos y consumidores de ficciones llenas de aventura, refinamiento y pasiones. En palabras de Ignacio Arellano, la de nuestra autora es «una escritura burguesa, más fluida y optimista que la rígida estructura reflejada en las novelas de María de Zayas» ${ }^{60}$. En una novela como El esclavo de su esclavo es evidente que Carvajal, so capa de una historia ambientada en una Cataluña medieval, crea su mundo propio, el de una burguesía o nobleza urbana, donde la lealtad, virtud de gente honrada, brinda el equilibrio necesario para un mundo unificado por un entorno agradable, aventuras con desenlaces felices y una sola religión verdadera. De esa forma, Mariana de Carvajal adaptó a su propia sensibilidad la lección del Abencerraje con su ejemplo de generosidad y la prolongó con la gratitud del moro noble que ayuda al caballero cristiano a escapar del cautiverio, que bien podría provenir de su lectura de El bien hacer no se pierde de Castillo Solórzano, la cual a su vez nos recuerda la lealtad del moro Muley (aunque nunca llegue a ponerse en acción), en El príncipe constante de Calderón. En conclusión, El esclavo de su esclavo muestra un diestro manejo de fuentes literarias puestas al servicio de una reconfiguración de la lealtad: encontramos la lección del Aben- 
cerraje, cierto, pero atemperada con la presencia del texto de Castillo Solórzano, la cual a su vez se engarza con la de Calderón, para plasmar en la novela de Carvajal la lealtad como virtud noble vuelta paradigma de conducta.

\section{Bibliografía}

Albert, Mechthild, «Sociabilidad y transmisión de saberes en la novela corta del Siglo de Oro», en Sociabilidad y literatura en el Siglo de Oro, ed. Mechthild Albert, Madrid / Frankfurt am Main, Iberoamericana / Vervuert, 2013, pp. 277-299.

Albert, Mechthild, «Modelos de masculinidad en las Navidades de Madrid (1663) de Mariana de Carvajal», en Nuevos enfoques sobre la novela barroca, ed. Mechthild Albert, Ulrike Becker, Rafael Bonilla Cerezo y Angela Fabris, Frankfurt am Main, Peter Lang, 2016, pp. 203-214.

Alcalde, Pilar, «Mariana de Carvajal y la representación de la ostentación», Crítica hispánica, 32, 2010, pp. 7-21.

Arellano, Ignacio, «La novela cortesana femenina de Mariana de Caravajal», Ínsula, 520, 1990, pp. 4-5.

Arellano, Ignacio, Historia del teatro español del siglo XVII, Madrid, Cátedra, 1995.

Armon, Shifra, Picking Wedlock. Women and the Courtship Novel in Spain, Lanham, Rowman \& Littlefield, 2002.

Armon, Sifra, Masculine Virtue in Early Modern Spain, Burlington, Ashgate Publishing Company, 2015.

Armon, Shifra, «11. Novelas y narraciones», en Las escritoras españolas de la Edad Moderna. Historia y guía para la investigación, ed. Nieves Baranda Leturio y Anne J. Cruz, Madrid, Universidad Nacional de Educación a Distancia, 2018, pp. 273-299.

Aut = Real Academia Española, Diccionario de autoridades, ed. facsímile, Madrid, Gredos, 1993.

Bollard, Kathleen, «Re-reading Heroism in El Abencerraje», Bulletin of Spanish Studies, 80.3, 2003, pp. 297-307.

Calderón de la Barca, Pedro, El príncipe constante, en Teatro, ed. José Bergamín, México, Océano, 1999, pp. 5-103.

Carrasco Urgoiti, María Soledad, «Una huella de El Abencerraje en Las Navidades de Madrid de Mariana de Carvajal (El esclavo de su esclavo)», en Estudios sobre la novela breve de tema morisco, Barcelona, Edicions Bellaterra, 2005, pp. 165-174.

Carvajal, Mariana de, El esclavo de su esclavo, en Entre la rueca y la pluma. Novela de mujeres en el Barroco, ed. Evangelina Rodríguez Cuadros y María Haro Cortés, Madrid, Biblioteca Nueva, 1999, pp. 429-448. 
Castillo Solórzano, Alonso de, Aventuras del bachiller Trapaza, ed. Jacques Joset, Madrid, Cátedra, 1986.

Castillo Solórzano, Alonso de, Noches de placer, ed. Emilio Cotarelo y Mori, Madrid, Librería de la Viuda de Rico, 1906.

Chevalier, Maxime, «La Diana de Montemayor y su público en la España del siglo XVI», en Creación y público en la literatura española, ed. Jean-François Botrel y Serge Salaün, Madrid, Castalia, 1974, pp. 40-55.

Díaz-Plaja, Fernando, Historia de España en sus documentos. Siglo XVII, Madrid, Cátedra, 1987.

Elliott, John H., Imperial Spain. 1469-1716, Middlesex, Penguin Books, 1972.

Gil-Osle, Juan Pablo, Amistades imperfectas: del Humanismo a la llustración con Cervantes, Madrid / Frankfurt am Main, Iberoamericana / Vervuert, 2013.

Herrero García, Miguel, Ideas de los españoles del siglo XVII, Madrid, Gredos, 1966.

Hutchinson, Steven, «Literatura fronteriza mediterránea: rasgos de un género literario», en Magis déficit manus et calamus quam eius historia: homenaje a Carlos Alvar, coord. Constance Carta, Sarah Finci, Dora Mancheva y Carlos Alvar Ezquerra, San Millán de la Cogolla, Cilengua, 2016, vol. 2, pp. 1431-1450.

Imperiale, Louis, «Woman of the World and World of the Woman in the Narrative of Mariana de Caravajal», en Women in the Discourse of Early Modern Spain, ed. Joan F. Cammarata, Gainesville, University Press of Florida, 2003, pp. 213-232.

Infante, Catherine, «La Virgen de Monserrat entre cristianos y musulmanes: el caso de El esclavo de su esclavo de Mariana de Carvajal», Sharq Al-Andalus, 22, 2017-2018, pp. 185-199.

Krömer, Wolfram, y Dunn, Peter N., «Los esquemas de la novela corta y la obra de Castillo Solórzano», en Historia y crítica de la literatura española. 3. Siglos de Oro: Barroco, ed. Bruce Wardropper, Barcelona, Crítica, 1983, pp. 517-524.

Martín Gómez, Moisés, Mariana de Carvajal: industrias y desdenes. Un estudio de las «Navidades de Madrid», Cádiz, Servicio de Publicaciones de la Universidad de Cádiz, 2003.

Montemayor, Jorge de, Los siete libros de la Diana, ed. Francisco López Estrada, Madrid, Espasa-Calpe, 1967.

Montoya, Jesús, «El frustrado cerco de Marrakech», Cuadernos de Estudios Medievales, 8-9, 1983, pp. 183-192.

Moya, Ismael, Romancero, II, Buenos Aires, Universidad de Buenos Aires, 1941.

Novelas cortas del siglo XVII, ed. Rafael Bonilla Cerezo, Madrid, Cátedra, 2010.

O'Brien, Eavan, «Verbalizing the Visual: María de Zayas, Mariana de Carvajal, and the Frame-Narrative Device», The Journal for Early Modern Cultural Studies, 12.3, 2012, pp. 117-142. 
Rodríguez Cuadros, Evangelina, Novela corta marginada del siglo XVII español. Formulación y sociología en José Camerino y Andrés de Prado, Valencia, Universidad de Valencia, 1979.

Romero-Díaz, Nieves, «Silence and Memory in Mariana de Carvajal's El esclavo de su esclavo», en Zayas and Her Sisters, 2: Essays on Novelas by $17^{\text {th }}$ Century Spanish Women, ed. Gwyn E. Campbell y Judith A. Whitenack, Binghamton, Global, 2001, pp. 203-217.

Romero-Díaz, Nieves, Nueva nobleza, nueva novela: reescribiendo la cultura urbana del Barroco, Newark, Juan de la Cuesta, 2002.

Teijeiro Fuentes, Miguel Ángel, Moros y turcos en la narrativa áurea (El tema del cautiverio), Cáceres, Universidad de Extremadura, 1988. 